
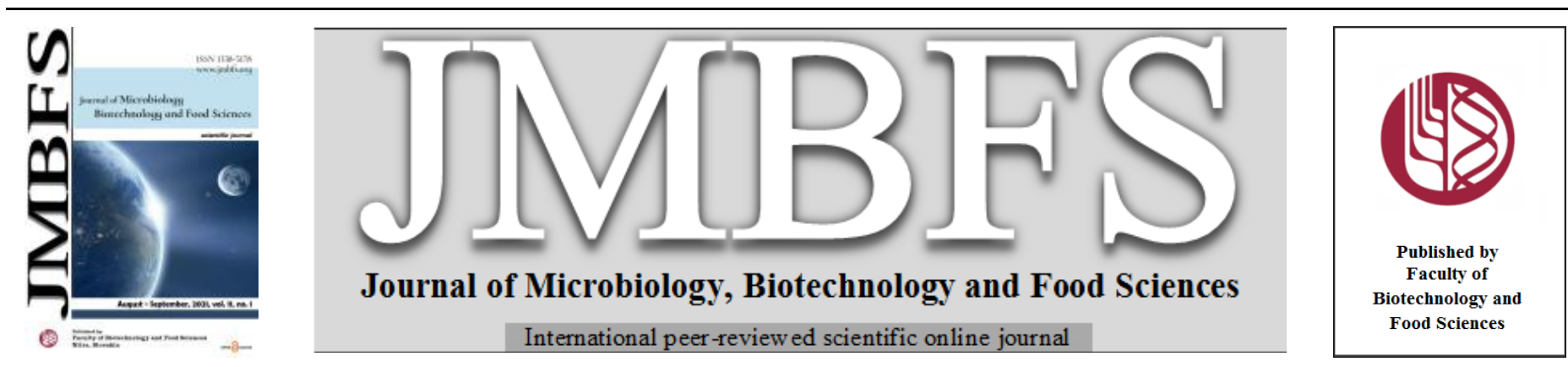

\title{
INVESTIGATION OF THE INFLUENCE OF ULTRAVIOLET LIGHT AND ULTRASOUND ON THE ANTIOXIDANT POTENTIAL, PHENOLIC CONTENT, AND STRUCTURAL-MECHANICAL PROPERTIES OF PEAR JAM ENRICHED WITH FIBERS
}

\author{
${\text { Zdravko } \text { Manev }^{1} \text {, Nadezhda Petkova }}^{2}$ \\ $\operatorname{Address}(e s)$ : \\ ${ }^{1}$ Institute of Food Preservation and Quality, Vasil Aprilov Blvd. 154, 4003 Plovdiv, Bulgaria \\ 2University of Food Technologies, Technological Faculty, Department of Organic Chemistry and Inorganic Chemistry, 26 Maritsa Blvd., 4002, Plovdiv, Bulgaria
}

*Corresponding author: z.manev44@gmail.com

https://doi.org/10.15414/jmbfs.4013

ARTICLE INFO

Received 28. 11. 2020

Revised 6. 2. 2021

Accepted 10. 2. 2021

Published 1. 8. 2021

Regular article

open $\mathcal{O}$ access

\begin{abstract}
This study aimed to investigate the effect of ultraviolet light and ultrasound on the antioxidant activity and rheological properties of pear fruit jam. The antioxidant potential of fruit jam was determined by three methods based on different mechanisms (DPPH ABTS and CUPRAC assays) in six samples treated with ultrasonic waves and ultraviolet light. The antioxidant activity and the content of total phenols were preserved to the greatest extent during the irradiation of the fruit jam with ultraviolet light at a wavelength of $254 \mathrm{~nm}$ for a certain time. Ultrasound irradiation reduces the antioxidant activity and lowers the content of total phenols to a greater extent than the ultraviolet light. In addition, seven types of rheological parameters were determined on the pear fruit jam by a texture analyzer and their changes during processing with ultraviolet light and ultrasound was studied. Ultraviolet light demonstrated a smaller reducing effect on the rheological parameters of the fruit jam compared to ultrasonic irradiation. From the obtained results, the irradiation with ultraviolet light should be considered as a better technique for treatment of pear jam with minor changes in the antioxidant potential, phenolic content, and structural mechanical properties of the final product.
\end{abstract}

Keywords: UV-C, ultrasound, antioxidants, polyphenols, rheological characteristics, jam

\section{INTRODUCTION}

The Santa Maria pear is an Italian variety imported to Bulgaria before more than 75 years ago. It is characterized by a sweet-sour taste, fruits ripen around the middle of July and the production yield is high. The characteristic of this pear variety is that the fruits stick to the tree and do not fall, like some other varieties. The pears are large, yellow, and have a red decoration on the side where they are illuminated by more sunlight. The physicochemical characteristics of Santa Maria pears vary depending on the region where they are grown and cultivated. As reported by Šbek (2018), Santa Maria pears from Montenegro have the total soluble dry matter $(11.99 \%)$, total titratable acidity $(0.54 \%)$ and $\mathrm{pH}(3.75)$ higher in values compared to the same variety from Bosnia and Herzegovina (Kulina et al., 2013). However, Santa Maria pears from Turkey showed the highest titratable acidity and total soluble dry matter (ک̌ebek, 2018). It has been scientifically proven that pears are a rich source of antioxidants. The antioxidants in pears have been found to suppress inflammatory processes in the human body, eliminate free radicals from cellular metabolism and reduce the risk of lung cancer in humans (Sanchez et al., 2003; Linseisen et al., 2007, Reiland \& Slavin, 2015). Moreover, pears contain vitamin A and its subsequent components such as lutein and zeaxanthin (Richard $\boldsymbol{e t}$ al., 2009). These substances are actively involved in many enzymatic reactions and act as antioxidants, which can reduce the formation of wrinkles, controlling the effect of aging on the skin. In addition, this fruit can reduce the likelihood of hair loss, macular degeneration, cataracts and various other conditions associated with the aging process (Ma $\boldsymbol{\&}$ Lin, 2010).

Fruits are a rich source of fibers. Dietary fibers are divided into two types depending on their solubility in water: soluble fiber $(\beta$-glucan, inulin, pectin and galactomannans) and insoluble fiber (cellulose, hemicellulose, lignin and chitosan) (Mudgil, 2017). Most of foods contain approximately one-third soluble and two-third insoluble fiber (Otles \& Ozgoz, 2014). Since pears are an excellent source of dietary fiber (Reiland \& Slavin, 2015), a serving portion of pears provides about $18 \%$ of the daily intake of dietary fiber which improves the function of the digestive system and reduces the energy intake, bring about bulking effect (Fuller et al., 2016). It was calculated that $71 \%$ of the total amount of fiber in pears, are insoluble, while $29 \%$ is soluble fibers (Slavin \&
Lloyd, 2012). Therefore, the jam obtained from the processing of the pear can be an interesting product from a nutritional point of view. In this respect, the appertisation could be replaced by other mild technologies, such as ultraviolet light and ultrasound treatments (Ansari et al., 2020; Petkova et al., 2020), that are more eco-friendly for the quality of the final product. The use of ultraviolet light, especially shortwave ultraviolet light (UV-C) is an innovative non-thermal technology for minimal food processing that not only improves food safety, enhances their appearance and nutrient content, but also extends the shelf life of food products (Cheigh et al., 2012; Koutchma et al., 2016). The advantages of UV-C comprise the absence of some toxic wastes or effects, low energy intake, low operating costs (Meléndez-Pizarro et al., 2020; Ricciardi et al., 2020). The use of UV-C leads to the minimal changes in nutritional and quality characteristics of foods, as well as microbiological safety assured by the inactivation of microbes in some liquid foods such as carambola, watermelon and pomegranate juice (Bhat et al., 2011; Zhang et al., 2011; Pala\& Toklucu, 2011). Another green method for non-thermal conservation of foods, especially fruit juices is the ultrasonic treatment.

Ultrasonic irradiation was applied in the processing of carrot, orange and red grape juices, as this technology improves their quality and safety - inactivate enzymes and microorganisms (Zou \& Jiang, 2016; Alabdali et al., 2020). The use of ultrasound in food technology can improve reaction conditions by lowering the temperature and reducing processing time with less external input (Ngo \& Ngo et al.,2017). The ultrasonic treatment does not have a significant effect on physicochemical parameters - pH, total soluble solids and titrable acidity in physalis (Yikmiş, 2020; Etzbach et al., 2019).

Therefore, the present study aimed to investigate the effect of ultraviolet light and ultrasound on the antioxidant potential and structural mechanical properties of fiber-enriched pear jam.

\section{MATERIAL AND METHODS}

\section{Preparation of fiber-enriched pear jam}

In a $125 \mathrm{ml}$ beaker, cellulose fibers $(2.5 \mathrm{~g})$ were added to aspartame $(0.1 \mathrm{~g})$ potassium sorbate $(0.045 \mathrm{~g})$ and $56.6 \mathrm{~g}$ of fruit puree of pears (variety - Santa 
Maria). The mixture was made up to $100 \mathrm{~g}$ with distilled water. The sample was homogenized and the volume was reduced by evaporation to the total soluble solids - $10 \%$ Brix. After that to the sample was added previously prepared dry mixture consisted of $1.0 \mathrm{~g}$ slow set sodium alginate and $0.8 \mathrm{~g}$ low-esterified amidated pectin. Distilled water $(20 \mathrm{~g})$ was added to the residue and the sample was mixed. The heating was performed to reduce the soluble solids to $12 \%$ Brix. The water losses due to evaporation comprise $18.7 \%$. The gelling process was performed by adding $7 \%$ calcium lactate pentahydrate for $20 \mathrm{~h}$ at room temperature. The fruit jam is then dried on kitchen paper to remove excess calcium salt after switching to the jelly formation. According to Regulation №1924 of 2006, the pear jam obtained before appertisation is a low-energy product $(35.86 \mathrm{kcal})$ and a source of fiber $(4.94 \%)$.

\section{Appertisation of the pear jam}

The treatment has been performed into an ultraviolet sterilizer - Towel Warmer model JY-502 with a power of $200 \mathrm{~W}$ when irradiated with ultraviolet light (UV) with a wavelength of $254 \mathrm{~nm}$ without heating the final product for 10,15 and 20 minutes, respectively. Ultrasonic treatment was performed in an ultrasonic bath (SIEL Gabrovo UST 5.7-150, BULGARIA) by ultrasound (US) with a power of $300 \mathrm{~W}$ and a frequency of $36 \mathrm{kHz}$ without heating only irradiating the fruit jam for 10,15 and 20 minutes, respectively. The colorless glass packages (glass bottles with a cut) were used in both treatments of the fruit jam from pears.

\section{Extraction of bioactive compounds}

The extraction of the biologically active components from the pear jam was performed by ultrasonic extraction with $70 \%$ ethanol in a solid to liquid ratio of 1:5 (w/v). The extraction was performed in triplicate in an ultrasonic bath (VWR, Malaysia) with a frequency of $45 \mathrm{kHz}$ and a power of $30 \mathrm{~W}$ at a temperature of $45^{\circ} \mathrm{C}$ (Petkova et al., 2017). Each extract was filtered and then was used for further analysis.

\section{Analysis of total phenols}

The content of total phenols in the obtained $70 \%$ ethanol extracts was determined using Folin - Ciocalteu`s reagent according to the described procedure (Stintzing et al., 2005). The results were presented as milligram equivalents of gallic acid per gram of sample (mg GAE/g), according to the calibration curve (Ivanov et al., 2018)

\section{Analysis of total flavonoids content}

The total flavonoids content was analyzed by $\mathrm{Al}\left(\mathrm{NO}_{3}\right)_{3}$ reagents and measured at wavelength $415 \mathrm{~nm}$ against a blank. The results were presented as mg quercetin equivalents $(\mathrm{QE})$ per g dw (Ivanov et al., 2018).

\section{Analysis of antioxidant activity.}

The antioxidant activity of the extracts obtained from the fruit jam after ultrasonic and ultraviolet exposure was determined by three methods based on different mechanisms DPPH and ABTS were based on mixed hydrogen atom transfer (HAT) and third method, based on electron transfer with their power to reduce cupric ions (CUPRAC).

DPPH assay. The extract $(0.15 \mathrm{ml})$ was mixed with $2.85 \mathrm{ml}$ of freshly prepared solution of DPPH (2,2-diphenyl-1-picrylhydrazyl) $(0.1 \mathrm{mM}$ in methanol). The reaction mixture was incubated in the dark for 15 minutes at $37{ }^{\circ} \mathrm{C}$. The absorbance reduction was read spectrophotometrically at $517 \mathrm{~nm}$ against the blank (Abbasi \& Shah, 2018).

ABTS assay. The ABTS radical was obtained by mixing equimolar amounts of ABTS (2,2'-azino-bis (3-ethylbenzothiazoline-6-sulphonic acid)), $7 \mathrm{mM}$ in distilled $\mathrm{H}_{2} \mathrm{O}$, and an aqueous solution of potassium persulfate $(2.45 \mathrm{mM})$ and kept for $16 \mathrm{~h}$ in the dark. Before analysis, $2 \mathrm{ml}$ of the ABTS radical was dissolved in methanol in a ratio of $1: 30 \mathrm{v} / \mathrm{v}$ to obtained $1.0 \div 1.1 \mathrm{AU}$ at $734 \mathrm{~nm}$. For analysis, $0.15 \mathrm{ml}$ extract was mixed with $2.85 \mathrm{ml}$ of freshly prepared ABTS radical solution. The reaction mixture was incubated in the dark for 15 minutes at $37^{\circ} \mathrm{C}$. The absorption reduction was read spectrophotometrically at a wavelength of $734 \mathrm{~nm}$ against a blank sample (Petkova et al., 2017).

CUPRAC assay. One $\mathrm{ml} \mathrm{CuCl}_{2} \times 2 \mathrm{H}_{2} \mathrm{O}, 1 \mathrm{ml}$ Neocuproin ( $7.5 \mathrm{mM}$ in methanol), $1 \mathrm{ml} 0.1 \mathrm{M}$ ammonium acetate buffer with $\mathrm{pH} 7.0 ; 0.1 \mathrm{ml}$ of test extract and $1 \mathrm{ml}$ distilled $\mathrm{H}_{2} \mathrm{O}$ was mixed. The reaction mixture was incubated for 20 minutes at $50^{\circ} \mathrm{C}$ in the dark. After cooling, the absorbance was measure at $450 \mathrm{~nm}$ (Petkova et al., 2017). The results of all three antioxidant methods were presented as millimoles of Trolox equivalents (mM TE) per gram sample.

\section{Determination of rheological indicators and structure-mechanical properties}

The characteristics as rupture force and rupture deformation of the pear jams were determined by penetration tests. For the analysis was used a Stable Microsystems Texture Analyser (SMS) in uniaxial deformation along the $\mathrm{Y}$-axis at a stress of $60 \%$ with a constant deformation rate of $2 \mathrm{~mm} / \mathrm{s}$ by an aluminum cylindrical piston with a diameter of $5 \mathrm{~mm}$. Six samples were measured to perform better statistics. The stress was calculated by dividing the rupture force by the cross-sectional area of the piston, which was $19,634 \mathrm{~cm}^{2}$ at the rupture point (Kohyama et al., 2019). Jam firmness indicated the resistance to penetration. It was determined by the slope of the first peak of the maximum rupture force and the depth of penetration (rupture deformation), reported in $\mathrm{N} / \mathrm{mm}$ (Harnkarnsujarit et al., 2016). Rupture energy is determined by calculating the area under the rupture force curve - rupture deformation (Cevher \& Öztekin, 2019) at the highest values. When toughness is measured in $\mathrm{J} / \mathrm{m}^{3}$ or a derivative of it, this is a mechanical property and is defined as the amount of energy that a material can absorb in a unit of volume before breaking (Berthaume, 2016). In this study, toughness was determined by a penetration test and represents the relationship between rupture energy and the volume of the product (material). The volume of the material is calculated as the product of the number " $\pi$ ", the radius of the piston raised into a square that penetrates the fruit jam and the rupture deformation - the height of the material when the piston penetrates it before the disruption of material. Stiffness was calculated as the ratio between the rupture force and the rupture deformation (Shirmohammadi $\&$ Fielke, 2017).

\section{Statistical analysis}

The obtained arithmetic mean values for the antioxidant activity, the content of total phenols and the data from the rheological measurements were processed with MS Excel 2007. Statistically significant differences between the values of the studied indicators compared to the control samples were determined by ANOVA (two-factor analysis without replication) at confidence level $\alpha=0.05$.

\section{RESULTS AND DISCUSSION}

\section{Antioxidant activity and polyphenolic content}

The results from the antioxidant activity and phenolic content were summarized in Table 1. The highest total phenolic content was detected in the control samples - $36 \mu \mathrm{g} \mathrm{GAE} / \mathrm{g}$, followed by P01 (Ultraviolet /10) and P02 (Ultraviolet /15) - 28 and $25 \mu \mathrm{g} \mathrm{GAE} / \mathrm{g}$, respectively. Twice lower results for total phenolic content were detected in samples treated by ultrasonic irradiation. The highest antioxidant activity has been detected in the control sample and P01 (Ultraviolet /10) and P02 (Ultraviolet /15) by the three methods DPPH, ABTS, and CUPRAC. The highest correlation $\mathrm{r}^{2}=0.9621$ was found between the total polyphenols and DPPH assay, followed by the total polyphenols and ABTS assay $\left(r^{2}=0.7823\right)$, while the lowest correlation was found between the total polyphenols and CUPRAC assay $\left(\mathrm{r}^{2}=0.5221\right)$. The lowest values of total phenols and antioxidant potential in the samples irradiated by ultrasonic waves could be explained with a cavitation process that could disrupt the cells and affect the phenolic compounds in the pear jam. In addition, any total flavonoids were not detected in all samples. A possible explanation is that most of the total flavonoids were situated in pear peel, which was removed before producing the pear jam production.

Table 1 Antioxidant activity and polyphenolic content of pear jam

\begin{tabular}{|c|c|c|c|c|c|}
\hline Sample № & Type of treatment/ time, min & $\begin{array}{c}\text { DPPH, mM } \\
\mathrm{TE}^{1} / \mathrm{g}\end{array}$ & $\begin{array}{c}\text { ABTS, mM } \\
\text { TE }^{1 / g}\end{array}$ & $\begin{array}{c}\text { CUPRAC, mM } \\
\text { TE }^{1} / \mathrm{g}\end{array}$ & $\begin{array}{c}\text { Total polyphenols, } \\
\mu \mathrm{g} \mathrm{GAE} / \mathrm{g}\end{array}$ \\
\hline Control - P00 & - & $0.30^{*} \pm 0.02^{\mathrm{a}}$ & $0.28^{*} \pm 0.04^{\mathrm{a}}$ & $0.33^{*} \pm 0.02^{\mathrm{a}}$ & $36.0^{*} \pm 1.1^{\mathrm{a}}$ \\
\hline $\mathrm{P} 01$ & Ultraviolet / 10 & $0.21 \pm 0.01^{\mathrm{b}}$ & $0.31 \pm 0.07^{\mathrm{b}}$ & $0.69 \pm 0.02^{\mathrm{b}}$ & $28.1 \pm 2.0^{\mathrm{b}}$ \\
\hline $\mathrm{P} 02$ & Ultraviolet / 15 & $0.24 \pm 0.00^{c}$ & $0.24 \pm 0.04^{\mathrm{c}}$ & $0.23 \pm 0.02^{\mathrm{c}}$ & $25.1 \pm 2.0^{\mathrm{c}}$ \\
\hline $\mathrm{P} 03$ & Ultraviolet / 20 & $0.10 \pm 0.00^{\mathrm{d}}$ & $0.25 \pm 0.08^{\mathrm{d}}$ & $0.14 \pm 0.01^{\mathrm{d}}$ & $16.5 \pm 2.0^{\mathrm{d}}$ \\
\hline $\mathrm{P} 04$ & Ultrasound / 10 & $0.09 \pm 0.02^{\mathrm{e}}$ & $0.19 \pm 0.05^{\mathrm{e}}$ & $0.19 \pm 0.02^{\mathrm{e}}$ & $16.2 \pm 2.0^{\mathrm{e}}$ \\
\hline $\mathrm{P} 05$ & Ultrasound / 15 & $0.09 \pm 0.02^{\mathrm{f}}$ & $0.16 \pm 0.05^{\mathrm{f}}$ & $0.17 \pm 0.02^{\mathrm{f}}$ & $13.3 \pm 5.1^{\mathrm{f}}$ \\
\hline P06 & Ultrasound / 20 & $0.19 \pm 0.01^{\mathrm{g}}$ & $0.22 \pm 0.04^{\mathrm{g}}$ & $0.02 \pm 0.01^{\mathrm{g}}$ & $22.2 \pm 0.8^{g}$ \\
\hline
\end{tabular}

Legend: ${ }^{1} \mathrm{mM}$ TE $-\mathrm{mM}$ Trolox equivalent; ${ }^{2} \mathrm{GAE}$ - gallic acid equivalents; ${ }^{*}$ mean values of six measurements $(\mathrm{n}=6) \pm$ standard deviation. The different letters in each line showed the statistically significant differences $(\mathrm{P}<0.05)$ compared to the control sample $(\mathrm{P} 00)$. 
The data of Table 1 showed that the total phenols content and antioxidant activity (especially evaluated by the DPPH method) reduced when the time of UV and ultrasound treatments increased from 10 to $20 \mathrm{~min}$ in comparison with the contro sample. Polyphenols are important biologically active compounds that have strong antioxidant activity. It has been scientifically proven that the antioxidant activity in the peel of different varieties of pears was higher compared to the fruit tissue (pulp) of the pear, and the content of total phenols in the peel of the pear was 6 to 20 times higher than the fruit tissue (Li et al., 2014). The current study demonstrated that when ultraviolet treatment was performed for 10 minutes, an increase in antioxidant activity (P01) evaluated by ABTS and CUPRAC methods was observed compared to the control sample. A similar effect associated with increased antioxidant activity (by the ABTS method) was observed when mango and pineapple are irradiated with ultraviolet light (UV-C) (George $\boldsymbol{e t}$ al., 2015; George et al., 2016). From the results shown in Table 1, it can be seen that the DPPH antioxidant activity (P01) and total phenols (P01) content were reduced to a small extent compared to the control. The longer treatment of the final product with ultraviolet light for $15 \mathrm{~min}$, a decrease in the antioxidant activity (P02) evaluated by the three methods and a significant reduction in the content of total phenols compared to P00 was observed. The current studies have shown that the values of antioxidant activity (P02) determined by DPPH, ABTS and CUPRAC methods were statistically indistinguishable from each other. From the performed rheological measurements it was found that when treating the fruit jam with ultraviolet light for 20 minutes (P03) there was a threefold or more than two-fold decrease in antioxidant activity by DPPH and CUPRAC methods compared to the control sample. A slight change in activity determined by the method of ABTS was observed. Ultraviolet exposure for 20 minutes affected the total phenols (P03) amount which was reduced slightly more than twice in a comparison with the sample P00.

As the duration of the ultrasonic treatment increased from 15 to 20 minutes, an increase in the antioxidant activity (P05; P06) determined by the DPPH and ABTS method and the content of total phenols was found. A similar effect associated with the increasing values of antioxidant activity and total phenols was found when red raspberry pulp was sonicated (Golmohamadi $\boldsymbol{e t}$ al., 2013). It has been established that high-power high-frequency ultrasound can lead to better maintenance of the initial quality of fruit pulps (Sulaiman et al., 2015; Etzbach et al., 2019) and thus applied to blueberry pulps (Etzbach $\boldsymbol{e t}$ al., 2019), apples, strawberries and pears (Sulaiman et al., 2015). The results presented in Table 1 showed that the antioxidant activity evaluated by the DPPH method was reduced more than three times compared to P00 when sonicated for $10 \mathrm{~min}$. The

$\underline{\text { Table } 2 \text { Structural mechanical properties of pear jam }}$ determined antioxidant activity (P04) by the ABTS and CUPRAC methods was statistically insignificant and lower than the P00 control.

From the results (Table 1), it can be seen that the content of total phenols (P04) in the ultrasonically treated sample for 10 minutes was identical to that in the ultraviolet treated sample for 20 minutes (P03). The antioxidant activity evaluated by the DPPH method (P04 and P05) during ultrasonic treatment for 10 and 15 minutes was 3.3 times lower than the control one (P00). The difference in antioxidant activity (P05) determined by ABTS and CUPRAC methods was statistically insignificant and lower in value than P00. The content of total phenols (P05) in the jam after ultrasonic treatment for 15 minutes was 2.7 times lower than the control sample (P00).

It was found that the antioxidant activity determined by the DPPH method (P06) during ultrasonic treatment for 20 minutes was lower than the control (P00). It was almost twice higher than the antioxidant activity determined for the same time (20 minutes) it was when irradiated with ultraviolet light (P03). The antioxidant activity (P06) determined by the ABTS method was reduced to a minimum in comparison to the control sample. The ultrasonic irradiation performed for $20 \mathrm{~min}$ on the fruit jam lead to a decrease in the value of antioxidant capacity (16.5 times) evaluated by the CUPRAC method (P06) compared to the control sample (P00). There was the same tendency for the antioxidant activity of the sample (P06) to decrease compared to the UV-treated sample for the same time (P03). The determined content of total phenols (P06) in the ultrasonic irradiated pear jam for 20 minutes was 1.6 times lower than the control sample (P00). The significant decrease in antioxidant activity by the CUPRAC method was most likely due to the additional treatment of the fruit jam with ultraviolet light and ultrasound. A similar effect associated with a large reduction in antioxidant potential by the CUPRAC method as a result of technological processing was observed in a mulberry jam (Tomas et al., 2017).

\section{Structural mechanical properties of pear jam}

The results from the structural mechanical properties of pear jam were reported in Table 2. The highest rupture force (P01) of fruit jam was obtained after ultraviolet light irradiation for 10 minutes. The lowest rupture force (P04) when irradiated with ultrasound for 10 minutes. From the presented experiments it was found that ultraviolet light or ultrasound slightly neglected the rupture deformation of the fruit jam compared to the control sample (P00). The rupture deformation showed the lowest value (P04) when treating fruit jam with ultrasound for 10 minutes. However, the highest value of rupture deformation was found (P05) when the sample was sonicated for 15 minutes.

Type of treatment/time, min

\begin{tabular}{|c|c|c|c|c|c|c|c|}
\hline \multirow[t]{3}{*}{$\begin{array}{l}\text { Rheological } \\
\text { characteristics }\end{array}$} & Control & UV10 & UV/15 & UV/20 & US/10 & US/15 & $\mathrm{US} / \mathbf{2 0}$ \\
\hline & \multicolumn{7}{|c|}{ Sample № } \\
\hline & P00 & P01 & P02 & P03 & P04 & P05 & P06 \\
\hline Rupture force $(\mathrm{N})$ & $1.10^{*} \pm 0.07^{\mathrm{a}}$ & $1.04^{*} \pm 0.06^{\mathrm{b}}$ & $0.96^{*} \pm 0.06^{\mathrm{c}}$ & $0.96^{*} \pm 0.05^{\mathrm{d}}$ & $0.92^{*} \pm 0.06^{\mathrm{e}}$ & $0.96^{*} \pm 0.07^{\mathrm{f}}$ & $0.98^{*} \pm 0.04^{\mathrm{g}}$ \\
\hline $\begin{array}{l}\text { Rupture } \\
\text { deformation } \\
(\mathrm{mm})\end{array}$ & $2.71 \pm 0.13^{\mathrm{a}}$ & $2.46 \pm 0.14^{\mathrm{b}}$ & $2.71 \pm 0.29^{c}$ & $2.72 \pm 0.11^{\mathrm{d}}$ & $2.57 \pm 0.17^{\mathrm{e}}$ & $2.76 \pm 0.13^{\mathrm{f}}$ & $2.63 \pm 0.17^{\mathrm{g}}$ \\
\hline $\operatorname{Stress}^{\mathrm{a}}(\mathrm{kPa})$ & $0.06 \pm 0.004^{\mathrm{a}}$ & $0.05 \pm 0.003^{b}$ & $0.05 \pm 0.003^{\mathrm{c}}$ & $0.05 \pm 0.003^{\mathrm{d}}$ & $0.05 \pm 0.003^{\mathrm{e}}$ & $0.05 \pm 0.004^{f}$ & $0.05 \pm 0.002^{\mathrm{g}}$ \\
\hline Firmness $^{\mathrm{a}}(\mathrm{N} / \mathrm{mm})$ & $0.39 \pm 0.04^{\mathrm{a}}$ & $0.40 \pm 0.01^{\mathrm{b}}$ & $0.34 \pm 0.03^{\mathrm{c}}$ & $0.34 \pm 0.02^{\mathrm{d}}$ & $0.34 \pm 0.03^{\mathrm{e}}$ & $0.33 \pm 0.03^{f}$ & $0.35 \pm 0.02^{g}$ \\
\hline $\begin{array}{l}\text { Rupture energy }{ }^{\mathrm{a}} \\
(\text { N.mm) }\end{array}$ & $1.54 \pm 0.10^{\mathrm{a}}$ & $1.31 \pm 0.17^{\mathrm{b}}$ & $1.29 \pm 0.22^{\mathrm{c}}$ & $1.37 \pm 0.12^{\mathrm{d}}$ & $1.22 \pm 0.14^{\mathrm{e}}$ & $1.31 \pm 0.14^{\mathrm{f}}$ & $1.29 \pm 0.12^{\mathrm{g}}$ \\
\hline $\begin{array}{l}\text { Toughness }^{\mathrm{a}} \\
\left(\mathrm{mJ} / \mathrm{cm}^{3}\right)\end{array}$ & $29.01 \pm 2.09^{\mathrm{a}}$ & $27.03 \pm 2.05^{\mathrm{b}}$ & $24.22 \pm 1.81^{\mathrm{c}}$ & $25.54 \pm 1.43^{\mathrm{d}}$ & $24.07 \pm 2.01^{\mathrm{e}}$ & $24.13 \pm 2.13^{\mathrm{f}}$ & $24.97 \pm 1.25^{\mathrm{g}}$ \\
\hline Stiffness $^{\mathrm{a}}(\mathrm{N} / \mathrm{mm})$ & $0.41 \pm 0.04^{\mathrm{a}}$ & $0.42 \pm 0.01^{\mathrm{b}}$ & $0.36 \pm 0.03$ & $0.35 \pm 0.02^{\mathrm{d}}$ & $0.36 \pm 0.03^{\mathrm{e}}$ & $0.35 \pm 0.03^{f}$ & $0.37 \pm 0.02^{\mathrm{g}}$ \\
\hline
\end{tabular}

Len vix measure

As the time of ultraviolet and ultrasonic treatment on the fruit jam increased, the breaking force $(\mathrm{P} 01 ; \mathrm{P} 02 ; \mathrm{P} 03 ; \mathrm{P} 04 ; \mathrm{P} 05 ; \mathrm{P} 06)$ was reduced to a very small extent compared to the control (P00). A similar effect of ultraviolet light associated with a decrease in hardness and fragility was observed in freshly cut pears (Garcia et al., 2013). A similar reducing effect to a minimum of ultrasound treated samples was observed in $\kappa$-carrageenan gels (Zendeboodi et al., 2019). The results presented in Table 2 showed that, regardless of the time and type of treatment on the final product, the compressive stress decreases slightly compared to the control (P00). Rheological studies have shown that the firmness of the jam (P02; $\mathrm{P} 03$; P04; P05; P06) was not affected by the type and time of irradiation and it was always lower in values than P00. A similar effect of ultraviolet light on firmness was observed in storing process of tomatoes (Mukhopadhyay et al., 2014). An exception was observed only in the treatment with ultraviolet light for 10 minutes, where the firmness of the jam (P01) was negligibly slightly higher than the other measured values. Ultrasonic irradiation for 10 to 20 minutes on the jam reduces the firmness. A similar effect of ultrasonic treatment for 10 minutes on firmness was observed in freshly sliced cucumbers during storage (Fan et al.,
2019). It was found that the highest firmness ( $P 01)$ was observed in the fruit jam treated with ultraviolet light for 10 minutes, and the lowest (P05) when treated with ultrasound for 15 minutes. The results presented in Table 2 showed that regardless of the type and time of irradiation, the breaking energy of the fruit jam is lower (P01; $\mathrm{P} 02$; $\mathrm{P} 03$; P04; $\mathrm{P} 05 ; \mathrm{P} 06)$ compared to P00. From the obtained rheological data it was established that in relation to P00 the highest breaking energy (P03) of the fruit jam is obtained when treated with ultraviolet light for 20 minutes, and the lowest value of breaking energy (P04) was observed when treated with ultrasound for 10 minutes. The rupture energy of pear fruit jam at a deformation rate of $2 \mathrm{~mm} / \mathrm{s}$ along the $\mathrm{Y}$-axis was from 4.7 to 5.3 times higher compared to black olives Gemlik (Kılıçkan \& Güner, 2008). Rheological studies have shown that the toughness of fruit jam was the same at the same time (10 minutes), but with different types of treatment (ultraviolet and ultrasonic) the highest value of toughness (P01) and the lowest toughness (P04) were observed The type of irradiation method used had a greater effect on the toughness than the irradiation time. In this study, it was found that the toughness of fruit jam, regardless of duration, was 9.1 to 10.1 times higher when irradiated with UV-C 
light and 9 to 9.3 times higher when treated with ultrasound compared to frozen fruit of Aegle marmelos Correa (Sonawane $\boldsymbol{\&}$ Pradhan, 2020). The data shown in Table 2 showed that regardless of the duration of the ultraviolet or ultrasonic treatment on the jam, the value of the rheological stiffness index was slightly reduced compared to the control sample (P00). When irradiation with ultraviolet light was performed for a certain time (10 minutes), a slight increase in the stiffness of the fruit jam was observed. A similar increase in stiffness under the action of ultraviolet light was reported in collagen hydrated with phosphate buffer saline (Schulze et al., 2018).

\section{CONCLUSION}

It was found that to a lesser extent, ultraviolet light retained the antioxidant activity (evaluated by the DPPH method) of the jam when irradiated for 10 to 15 minutes relative to ultrasound for the same time. The antioxidant activity (ABTS and CUPRAC methods) and the content of total phenols were preserved to the greatest extent when the fruit jam was irradiated with ultraviolet light for 10 minutes compared to the control sample (P00). The treatment with ultraviolet light for 10 minutes and ultrasound for 20 minutes caused the least reduction in rheological parameters - rupture force, firmness, toughness, and stiffness compared to the control sample. Ultraviolet light and ultrasound do not significantly affect the stress of fruit jam. When the final product was treated with ultraviolet light for 20 minutes and ultrasound for 15 minutes, the rupture deformation and rupture energy were reduced to a lesser extent. In the production of fruit jam from pears, the use of ultraviolet light is recommended due to the lower cost of technological equipment, preservation of biologically valuable components to a greater extent, and shorter time impact on the final product compared to ultrasonic treatment.

Acknowledgments: This experimental work was financially supported by the Ministry of Education and Science of Bulgaria for funding basic research for young scientists and Ph.D. students - 2018 on the research project "Production of low-calorie fruit jam from pears enriched with fibers" and contract number KП06-M27/8 from 08.12.2018.

\section{REFERENCES}

Abbasi, A. M., \& Shah, M. H. (2018). Assessment of phenolic contents, essential / toxic metals and antioxidant capacity of fruits of viburnum foetens decne. Biointerface Research in Applied Chemistry, 8(3), 3178-3186.

Alabdali, TA, Icyer, NC, Ucak Ozkaya, G., \& Durak, MZ (2020). Effect of standalone and combined ultraviolet and ultrasound treatments on physicochemical and microbial characteristics of pomegranate juice. Applied Sciences, 10 (16) 5458. http://dx.doi.org/10.3390/app10165458

Ansari, J. A., Ismail, M., \& Farid, M. (2020). Extension of shelf life of pasteurized trim milk using ultraviolet treatment. Journal of Food Safety, 40(2), e12768. https://doi.org/10.1111/jfs. 12768

Berthaume, M. A. (2016). Food mechanical properties and dietary ecology. American Journal of Physical Anthropology, 159, 79-104. http://dx.doi:10.1002/ajpa.22903

Bhat, R., Ameran, S. B., Voon, H. C., Karim, A. A., \& Tze, L. M. (2011) Quality attributes of starfruit (Averrhoa carambola L.) juice treated with ultraviolet radiation. Food Chemistry, 127(2), 641-644. http://dx.doi.org/10.1016/j.foodchem.2011.01.042

Cevher, E. Y., \& Öztekin, Y. B. (2019). Mechanical behavior of Deveci pear cultivar affected by maturation. Turkish Journal of Food and Agriculture Sciences, 1(2), 39-43. http://dx.doi:10.14744/turkjfas.2019.008

Cheigh, C. I., Park, M. H., Chung, M. S., Shin, J. K., \& Park, Y. S. (2012). Comparison of intense pulsed light-and ultraviolet (UVC)-induced cell damage in Listeria monocytogenes and Escherichia coli O157: H7. Food Control, 25(2), 654-659. http://dx.doi.org/10.1016/j.foodcont.2011.11.032

Etzbach, L., Pfeiffer, A., Schieber, A., \& Weber, F. (2019). Effects of thermal pasteurization and ultrasound treatment on the peroxidase activity, carotenoid composition, and physicochemical properties of goldenberry (Physalis peruviana L.) puree. LWT-Food Science and Technology, 100, 69-74. http://dx.doi.org/10.1016/j.lwt.2018.10.032

Fan, K., Zhang, M., \& Jiang, F. (2019). Ultrasound treatment to modified atmospheric packaged fresh-cut cucumber: influence on microbial inhibition and storage quality. Ultrasonics sonochemistry, 54, 162-170. http://dx.doi.org/10.1016/j.ultsonch.2019.02.003

Fuller, S., Beck, E., Salman, H., \& Tapsell, L. (2016). New horizons for the study of dietary fiber and health: A Review. Plant Foods for Human Nutrition, 71(1), 1-12.http://dx.doi:10.1007/s11130-016-0529-6

Galvis Sánchez, A. C., Gil-Izquierdo, A., \& Gil, M. I. (2003). Comparative study of six pear cultivars in terms of their phenolic and vitamin $\mathrm{C}$ contents and antioxidant capacity. Journal of the Science of Food and Agriculture, 83(10), 995-1003. http://dx.doi:10.1002/jsfa.1436

Garcia Loredo, A. B., Guerrero, S. N., \& Alzamora, S. M. (2013). Impact of combined ascorbic acid/CaCl2, hydrogen peroxide and ultraviolet light treatments on structure, rheological properties and texture of fresh-cut pear
(William var.). Journal of Food Engineering, 114(2),

$164-$ 173.http://dx.doi:10.1016/i.jfoodeng.2012.08.017

George, D. S., Razali, Z., Santhirasegaram, V., \& Somasundram, C. (2015) Effects of ultraviolet light (UV-C) and heat treatment on the quality of fresh-cut chokanan mango and josephine pineapple. Journal of Food Science, 80(2), S426S434. http://dx.doi:10.1111/1750-3841.12762

George, D. S., Razali, Z., Santhirasegaram, V., \& Somasundram, C. (2016). Effect of postharvest ultraviolet-C treatment on the proteome changes in fresh cut mango (Mangifera indica L. cv. Chokanan). Journal of the Science of Food and Agriculture, 96(8), 2851-2860. http://dx.doi:10.1002/jsfa.7454

Golmohamadi, A., Möller, G., Powers, J., \& Nindo, C. (2013). Effect of ultrasound frequency on antioxidant activity, total phenolic and anthocyanin content of red raspberry puree. Ultrasonics Sonochemistry, 20(5), 1316-1323. http://dx.doi:10.1016/j.ultsonch.2013.01.020

Harnkarnsujarit, N., Kawai, K., \& Suzuki, T. (2016). Impacts of freezing and molecular size on structure, mechanical properties and recrystallization of freezethawed polysaccharide gels. LWT - Food Science and Technology, 68, 190-201. http://dx.doi:10.1016/j.lwt.2015.12.030

Ivanov, I., Petkova, N., Tumbarski, J., Dincheva, I., Badjakov, I., Denev, P. \& Pavlov, A. (2018). GC-MS characterization of n-hexane soluble fraction from dandelion (Taraxacum officinale Weber ex F.H. Wigg.) aerial parts and its antioxidant and antimicrobial properties. Zeitschrift für Naturforschung C, 73(12), 41-47. https://doi.org/10.1515/znc-2017-0107

Kanatt, S. R., Siddiqui, A., \& Chawla, S. P. (2018). Antioxidant/antimicrobial potential of Emblica officinalis Gaertn and its application as a natural additive for shelf life extension of minced chicken meat. Biointerface Research in Applied Chemistry, 8(4), 3344-3350. https://elibrary.ru/item.asp?id=35608184

Kilıçkan, A., \& Güner, M. (2008). Physical properties and mechanical behavior of olive fruits (Olea europaea L.) under compression loading. Journal of Food Engineering, 87(2), 222-228. http://dx.doi.org/10.1016/j.jfoodeng.2007.11.028

Kıvrak, I., Duru, M., Öztürk, M., Mercan, N., Harmandar, M., Topçu, G. (2009). Antioxidant, anticholinesterase and antimicrobial constituents from the essential oil and ethanol extract of Salvia potentillifolia. Food Chemistry, 116(2), 470-479 https://doi.org/10.1016/j.foodchem.2009.02.069

Kohyama, K., Ishihara, S., Nakauma, M., \& Funami, T. (2019). Compression Test of Soft Food Gels Using a Soft Machine with an Artificial Tongue. Foods, 8(6), 182. http://dx.doi:10.3390/foods8060182

Koutchma, T., Popović, V., Ros-Polski, V., \& Popielarz, A. (2016). Effects of ultraviolet light and high-pressure processing on quality and health-related constituents of fresh juice products. Comprehensive Reviews in Food Science and Food Safety, 15(5), 844-867. http://dx.doi.org/10.1111/1541-4337.12214

Kulina, M., Radović, M., Berjan, S., \& Kraišnik, V. (2013). Pomological and chemical characteristics of fruit of some pear cultivars grown in conditions of Bratunac. Agroznanje-Agro-knowledge Journal, 14(3),

$357-365$. http://dx.doi:10.7251/agrsr1303357k

Li, X., Wang, T., Zhou, B., Gao, W., Cao, J., \& Huang, L. (2014). Chemical composition and antioxidant and anti-inflammatory potential of peels and flesh from 10 different pear varieties (Pyrus spp.). Food chemistry, 152, 531-538. http://dx.doi.org/10.1016/j.foodchem.2013.12.010

Linseisen, J., Rohrmann, S., Miller, A. B., Bueno-de-Mesquita, H. B., Büchner, F. L., Vineis, P., Riboli, E. (2007). Fruit and vegetable consumption and lung cancer risk: Updated information from the European Prospective Investigation into Cancer and Nutrition (EPIC). International Journal of Cancer, 121(5), 11031114. http://dx.doi:10.1002/ijc.22807

Ma, L., \& Lin, X.-M. (2010). Effects of lutein and zeaxanthin on aspects of eye health. Journal of the Science of Food and Agriculture, 90(1), 2-12. http://dx.doi: $10.1002 /$ jsfa. 3785

Meléndez-Pizarro, C. O., Calva-Quintana, A., Espinoza-Hicks, J. C., SánchezMadrigal, M. Á., \& Quintero-Ramos, A. (2020). Continuous flow UV-C irradiation effects on the physicochemical properties of aloe vera gel and pitaya (Stenocereus spp.) blend. Foods, 9(8),

1068.

http://dx.doi.org/10.3390/foods 9081068

Mudgil, D. (2017). The interaction between insoluble and soluble fiber. Dietary Fiber for the Prevention of Cardiovascular Disease, 35-59. http://dx.doi:10.1016/b978-0-12-805130-6.00003-3

Mukhopadhyay, S., Ukuku, D. O., Juneja, V., \& Fan, X. (2014). Effects of UV-C treatment on inactivation of Salmonella enterica and Escherichia coli $\mathrm{O} 157: \mathrm{H} 7$ on grape tomato surface and stem scars, microbial loads, and quality. Food Control, 44, 110-117. http://dx.doi:10.1016/j.foodcont.2014.03.027

Ngo, T. H. D., \& Ngo, D. N. (2017). Effects of low-frequency ultrasound on heterogenous deacetylation of chitin. International journal of biological macromolecules, 104 ,

http://dx.doi.org/10.1016/j.ijbiomac.2017.03.117

Ötles, S., \& Ozgoz, S. (2014). Health effects of dietary fiber. Acta Scientiarum Polonorum Technologia Alimentaria, 13(2), 191-202. http://dx.doi:10.17306/j.afs.2014.2.8

Pala, Ç. U., \& Toklucu, A. K. (2011). Effect of UV-C light on anthocyanin content and other quality parameters of pomegranate juice. Journal of Food Composition and Analysis, 24(6),

http://doi.org/10.1016/j.jfca.2011.01.003 
Petkova, N., Ivanov, I., Vrancheva, R., Denev, P., \& Pavlov, A. (2017) Ultrasound and microwave-assisted extraction of elecampane (Inula helenium) roots. Natural product communications, 12(2), 171-174. https://doi.org/10.1177/1934578X1701200207

Petkova, N., Ivanov, I., Mihaylova, D., \& Lante, A. (2020). Effect of pressure liquid extraction and ultrasonic irradiation frequency on inulin, phenolic content and antioxidant activity in burdock (Arctium lappa L) roots. Acta Scientiarum $\begin{array}{llll}\text { Polonorum Hortorum } \quad \text { Cultus, } & 19(3), & 125-133\end{array}$ http://dx.doi:10.24326/asphc.2020.3.11

Reiland, H., \& Slavin, J. (2015). Systematic review of pears and health. Nutrition Today, 50(6), 301-305. http://dx.doi:10.1097/nt.0000000000000112

Ricciardi, E. F., Pedros-Garrido, S., Papoutsis, K., Lyng, J. G., Conte, A., \& Del Nobile, M. A. (2020). Novel technologies for preserving ricotta cheese: effects of ultraviolet and near-ultraviolet-visible light. Foods, 9(5), 580 http://dx.doi.org/10.3390/foods9050580

Roberts, R. L., Green, J., \& Lewis, B. (2009). Lutein and zeaxanthin in eye and skin health. Clinics in Dermatology, 27(2), 195-201. http://dx.doi:10.1016/j.clindermatol.2008.01.011

Schulze, M., Rogge, M., \& Stark, R. W. (2018). Atomic force microscopy measurements probing the mechanical properties of single collagen fibrils under the influence of UV light in situ. Journal of the Mechanical Behavior of Biomedical Materials, 88, 415-421. http://dx.doi:10.1016/j.jmbbm.2018.08.039

Šebek, G. (2018). Chemical and pomological characteristics of fruit of some commercial pear cultivars grown in conditions of Bjelo Polje. Journal of Hygienic Engineering and Design, 25, 56-61.

Shirmohammadi, M., \& Fielke, J. (2017). Conditioning reduces kernel damage when impact shelling almonds. International Journal of Food Engineering, 13(8). http://dx.doi:10.1515/ijfe-2016-0324

Slavin, J. L., \& Lloyd, B. (2012). Health benefits of fruits and vegetables. Advances in Nutrition, 3(4), 506-516. http://dx.doi:10.3945/an.112.002154

Sonawane, A., Pathak, S. S., \& Pradhan, R. C. (2020). Physical, thermal, and mechanical properties of bael fruit. Journal of Food Process Engineering, 43(6), e13393. http://dx.doi:10.1111/jfpe.13393

Stintzing, F. C., Herbach, K. M., Mosshammer, M. R., Carle, R., Yi, W., Sellappan, S., Felker, P. (2005). Color, betalain pattern, and antioxidant properties of cactus pear (Opuntia spp.) clones. Journal of Agricultural and Food Chemistry, 53(2), 442-451. http://dx.doi:10.1021/jf048751y

Sulaiman, A., Soo, M. J., Farid, M., \& Silva, F. V. M. (2015). Thermosonication for polyphenoloxidase inactivation in fruits: Modeling the ultrasound and thermal kinetics in pear, apple and strawberry purees at different temperatures. Journal of Food Engineering, 165, 133-140. http://dx.doi:10.1016/j.jfoodeng.2015.06.020 Tomas, M., Toydemir, G., Boyacioglu, D., Hall, R. D., Beekwilder, J., \& Capanoglu, E. (2017). Processing black mulberry into jam: effects on antioxidant potential andin vitrobioaccessibility. Journal of the Science of Food and Agriculture, 97(10), 3106-3113. http://dx.doi:10.1002/jsfa.8152

Y1kmış, S. (2020). Effect of ultrasound on different quality parameters of functional sirkencubin syrup. Food Science and Technology, 40(1), 258-265. http://dx.doi.org/10.1590/fst.40218

Zendeboodi, F., Farahnaky, A., \& Gholian, M. M. (2019). Structural changes and stress relaxation behavior of $\kappa$-carrageenan cold-processed gels: Effects of ultrasonication time and power. Journal of Texture Studies, 50(6), 465-473. http://dx.doi:10.1111/jtxs.12457

Zhang, C., Trierweiler, B., Li, W., Butz, P., Xu, Y., Rüfer, C. E., \& Zhao, X. (2011). Comparison of thermal, ultraviolet-c, and high pressure treatments on quality parameters of watermelon juice. Food Chemistry, 126(1), 254-260. http://dx.doi.org/10.1016/j.foodchem.2010.11.013

Zou, Y., \& Jiang, A. (2016). Effect of ultrasound treatment on quality and microbial load of carrot juice. Food Science and Technology, 36(1), 111-115 http://dx.doi.org/10.1590/1678-457X.0061 